\title{
A comparative study of gallstones from children and adults using FTIR spectroscopy and fluorescence microscopy Oleg Kleiner ${ }^{1}$, Jagannathan Ramesh ${ }^{2}$, Mahmoud Huleihel ${ }^{3}$, Beny Cohen ${ }^{4}$, Keren Kantarovich ${ }^{2}$, Chen Levi ${ }^{2}$, Boris Polyak ${ }^{3}$, Robert S Marks ${ }^{3}$, Jacov Mordehai ${ }^{1}$, Zahavi Cohen ${ }^{1}$ and Shaul Mordechai*2
}

Address: ${ }^{1}$ Department of Pediatric Surgery, Soroka University Medical Center, Ben Gurion University, Beer Sheva 84101 Israel, 2 Department of Physics, Ben Gurion University, Beer Sheva, 84105, Israel, ${ }^{3}$ The Institute for Applied Biosciences, Ben Gurion University, Beer Sheva, 84105 , Israel and ${ }^{4}$ Department of Chemistry, Ben Gurion University, Beer Sheva, 84105, Israel

E-mail: Oleg Kleiner - finaly@bgumail.bgu.ac.il; Jagannathan Ramesh - jram@bgumail.bgu.ac.il;

Mahmoud Huleihel - mahmoudh@bgumail.bgu.ac.il; Beny Cohen - bcohen@bgumail.bgu.ac.il; Keren Kantarovich - kerenk@bgumail.bgu.ac.il; Chen Levi - chenle@bgumail.bgu.ac.il; Boris Polyak - polyak@bgumail.bgu.ac.il; Robert S Marks - rsmarks@bgumail.bgu.ac.il;

Jacov Mordehai - mordehai@bgumail.bgu.ac.il; Zahavi Cohen - zahavic@bgumail.bgu.ac.il; Shaul Mordechai* - shaulm@bgumail.bgu.ac.il

*Corresponding author

Published: II February 2002

BMC Gastroenterology 2002, 2:3
Received: I3 November 200 |

Accepted: II February 2002

This article is available from: http://www.biomedcentral.com/I47I-230X/2/3

(c) 2002 Kleiner et al; licensee BioMed Central Ltd. Verbatim copying and redistribution of this article are permitted in any medium for any purpose, provided this notice is preserved along with the article's original URL.

\begin{abstract}
Background: Cholelithiasis is the gallstone disease (GSD) where stones are formed in the gallbladder. The main function of the gallbladder is to concentrate bile by the absorption of water and sodium. GSD has high prevalence among elderly adults. There are three major types of gallstones found in patients, White, Black and Brown. The major chemical component of white stones is cholesterol. Black and brown stones contain different proportions of cholesterol and bilirubin. The pathogenesis of gallstones is not clearly understood. Analysis of the chemical composition of gallstones using various spectroscopic techniques offers clues to the pathogenesis of gallstones. Recent years has seen an increasing trend in the number of cases involving children. The focus of this study is on the analysis of the chemical composition of gallstones from child and adult patients using spectroscopic methods.
\end{abstract}

Methods: In this report, we present FTIR spectroscopic studies and fluorescence microscopic analysis of gallstones obtained from 67 adult and $2 \mathrm{I}$ child patients. The gallstones were removed during surgical operations at Soroka University Medical Center.

Results: Our results show that black stones from adults and children are rich in bilirubin. Brown stones are composed of varying amounts of bilirubin and cholesterol. Green stones removed from an adult, which is rare, was found to be composed mainly of cholesterol. Our results also indicated that cholesterol and bilirubin could be the risk factors for gallstone formation in adults and children respectively. Fluorescence micrographs showed that the Ca-bilirubinate was present in all stones in different quantities and however, Cu-bilirubinate was present only in the mixed and black stones.

Conclusions: Analysis based on FTIR suggest that the composition of black and brown stones from both children and adults are similar. Various layers of the brown stone from adults differ by having varying quantities of cholesterol and calcium carbonate. Ring patterns observed mainly in the green stone using fluorescence microscopy have relevance to the mechanism of the stone formation. Our preliminary study suggests that bilirubin and cholesterol are the main risk factors of gallstone disease. 


\section{Background}

Gallstone disease remains a serious health concern affecting millions throughout the world $[1,2]$. The formation of gallstones in vivo takes years and it is quite difficult to monitor such events from nucleation to the consolidation [3]. Gallstone formation is therefore very poorly understood. Surprisingly, in the last few decades there has been significant rise in gallstone disease among children [4-6]. The vast majority of the reports are on adults [7]. Removal of the gallbladder by surgical methods is the only solution available to the gallstone disease today and therefore, the disease has a strong impact on children. The main function of the gallbladder is to concentrate bile by absorption of water and sodium. It concentrates the impermeable solutes contained in the hepatic bile by a factor of 5 to 10 and reducing its volume by $80-90 \%$. Gallstones made up of different compositions display various colors. There are three major types of stones observed in patients. These are a) white b) black and c) brown stones. This classification based on the color, was proposed at the NIH workshop [8]. Earlier FTIR and FT-Raman studies suggested an additional category called mixed stones having different proportions of cholesterol and bilirubin [7]. Black and brown color stones contain bilirubin in large amounts in addition to small quantities of cholesterol. The pigmented stones can be further sub-categorized on the basis of minor variations in chemical composition, such as the presence of calcium carbonate. Three main lipids found in the bile are bile acids, cholesterol and phospholipids [9].

FTIR spectroscopy has been widely applied for structural studies on variety of biomolecules [10]. In the past few years, the use of FTIR method has enhanced our understanding in different branches of medicine. Diagnosis of cancer types such as lung, breast and colon may become a reality in the future [11-13]. There are interesting reports in the literature on the FTIR characterization of gallstones and kidney stones from adults $[14,15]$. But there are no reports on the FTIR studies related to cases of children, which is becoming alarmingly important in recent years. In the present report, we present comparative results on FTIR characterization of various types of gallstones from both adults and children. In addition, we have characterized various gallstones using fluorescence microscopy (FM), which provided insights into the various fluorophores present in the stones.

\section{Materials and Methods Gallstone extraction}

Expert surgeons from the department of Pediatric surgery extracted the gallstones during surgery. Initially, the gallbladder from patients was surgically removed in the department of Pediatric surgery using a Laparoscopic Cholecystectomy procedure. The gallstones were extracted from the gallbladder and preserved under sterile condi- tions. The patients consisted of both children and adults. Gallstones samples were collected from 67 adult and 21 child patients for this study. GSD (Gall Stone Disease) is relatively less common among children in comparison to adult population and hence the number of child patients taken for this study was limited. Helsinki agreement was obtained to carry out this project at SUMC (Soroka University Medical Center) and consent was obtained from all patients to use the isolated stones for research purpose. All stone samples were stored in sterile dried condition and later used for FTIR and Fluorescence microscopic analysis.

\section{FTIR spectroscope}

The FTIR measurements were performed using JASCO615 FTIR spectrometer in the frequency range $400-4000 \mathrm{~cm}^{-1}$ at $4 \mathrm{~cm}^{-1}$ resolution. To obtain a high signal/noise ratio 128 scans were accumulated for each sample. Initially, the spectra were fitted to parabolic function. Then the RMS (Root Mean Square) was calculated between the original spectrum and the one, fitted by the function. The area under the fitted spectrum was divided by the noise RMS, which is reported as Signal/ Noise Ratio (SNR). The Evaluate menu provided in the OPUS software performed the entire process automatically. As prescribed by Bruker, SNR was calculated in the range $1900-2100 \mathrm{~cm}^{-1}$

For each measurement 4-8 $\mathrm{mg}$ of finely powdered stone sample was used to make $\mathrm{KBr}$ discs. Control spectra were acquired for cholesterol, bilirubin and calcium carbonate which were of high quality (99\% pure) and purchased from Sigma Chemical Company. In the case of FTIR-ATR measurements, only stone powder was used. The horizontal ATR (HATR) setup from PIKE technologies was used. The ZnSe crystal in the ATR setup was $80 \times 10 \mathrm{~mm}$ and its thickness was $4 \mathrm{~mm}$. Vector normalization was applied to all the FTIR spectra reported in this study. Out of 67 adult and 21 child stones, which were measured, the spectra having signal/noise above 800 are presented in this study.

\section{Fluorescence microscope}

The stone samples were visualized on an Olympus SZX 12 fluorescent research stereomicroscope adapted with two standard filter sets. One allowed blue excitation for observation in the green (filter1) (GFP, YFP etc. excitation filter BP460-490 nm, absorption filter BA510IF, dichroic mirror DM505) and the other allowed green excitation for observation in the red (filter2) (TRITC dying etc., excitation filter 460-560 nm, absorption filter O-590, dichroic mirror DM580). The total magnification range was between $11 \times-144 \times$. A $100 \mathrm{~W}$ mercury lamp made illumination of samples. Photographs were taken with an Olympus Camedia C-3030 Zoom digital camera adapted to the microscope. The image size of each photo was 2048 $\times 1536$ pixels. 


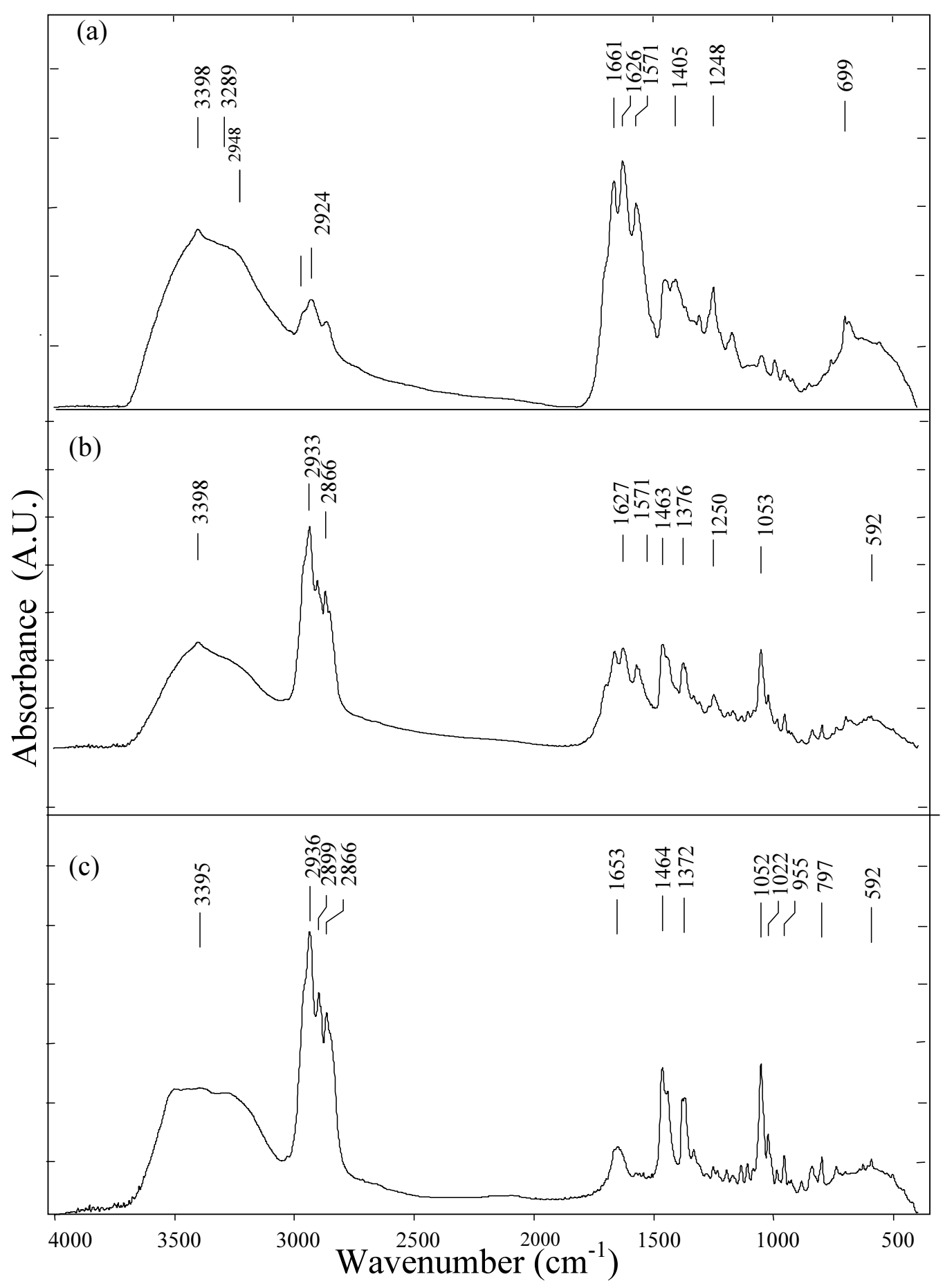

Figure I

FTIR spectra of a) Type I black stone b) Type II black stone c) brown stone from adult patients. Vector normalization was applied to the spectra in Figures I,2,3,4,5,6,7. The spectra presented in figure I are the averages of 12 and 10 black and brown stones respectively. 


\section{Results}

FTIR Spectroscopy of black and brown stones from adults Average FTIR spectra of black (12 stones) and brown (10 stones) stones from adults are shown in Figure 1 ( $1 \mathrm{a}, 1 \mathrm{~b}$ \& 1c). Even though FTIR data was collected on 88 patients (67 adults and 21 children), only representative spectra from 35 patients are presented in this study. Our results showed that there were two families of black stones (labeled a \& b) observed by the FTIR method. Both types of black stones showed characteristic bands in the region between 1500-1700 $\mathrm{cm}^{-1}$ due to the stretching vibrations of $\mathrm{C}=\mathrm{C}, \mathrm{CO}$ and $\mathrm{C}-\mathrm{N}$ at 1570, 1626, 1661 and 1700 arising from bilirubinate salts $[7,16]$. To make the identification of IR bands simpler, the reference spectra of cholesterol, bilirubin and calcium carbonate are presented in Figure 2 (2a,2b \& 2c). Also, the triplet between $1500-1700 \mathrm{~cm}^{-1}$ is an indication of bilirubinate in the metal complexed form whereas a doublet characterizes the unconjugated bilirubin. The type of stone, the principal chemical components of each type and its corresponding IR bands from our study along with literature values are given in Table 1. The strong bands around $1050 \mathrm{~cm}^{-1}$ from one of the brown stones (Figure 1c) as well as the black stone (type II) shown in the figure (Figure 1b) confirm the existence of cholesterol. It can be a mixed stone by chemical composition having cholesterol along with pigment components Cholesterol in the brown and black stones was characterized by the bands between $2800-3000 \mathrm{~cm}^{-1}$ due to asymmetric and symmetric stretching vibrations of $\mathrm{CH}_{2}$ and $\mathrm{CH}_{3}$ groups [17]. The other black stone (type II)) contained less cholesterol as the absorbance of the $\mathrm{CH}_{2}$ and $\mathrm{CH}_{3}$ vibrations was relatively much lower compared to the other two shown in Figure 1.

\section{FTIR spectra of black and green stones from adults}

In the literature, the reported colors of pigmented stones observed extensively in patients are black and brown. For the first time, our group has identified a green color gallstone from an adult patient. It was green in color all over the surface. The FTIR spectra of green and black (type II) gallstones obtained from adults are shown in Figure $3 a$, $3 \mathrm{~b} \& 3 \mathrm{c}$. The spectrum for the green stone in the region between 1400-1800 $\mathrm{cm}^{-1}$ was entirely different from the black stone. This is due to the varying cholesterol content of these stones. Black stones contained high amounts of cholesterol and lower quantities of bilirubin. In contrast, the cholesterol was a major component of the green stone, with much less content of bilirubin. This is evident in the spectra in the region between $2800-3000 \mathrm{~cm}^{-1}$ shown in Figure $3 \mathrm{~b} \& 3 \mathrm{c}$. Also, the FTIR spectra of the outer surface and the inner core of the green stone were measured. The results showed that the inner core had slightly more cholesterol content than the outside surface.

\section{Comparison of FTIR-ATR and regular FTIR of brown stones from an adult}

FTIR-Attenuated Total Reflection (FTIR-ATR) has become a powerful tool in the studies of the structure of biological materials and biomaterial surfaces $[18,19]$. Figure $4 \mathrm{a} \& 4 \mathrm{~b}$ shows the FTIR-ATR and regular FTIR spectra of the entire and part of the surface of a brown stone. There were significant differences in the spectra by these two different methods. The IR bands between 1300-1500 and 1000$1100 \mathrm{~cm}^{-1}$ showed that the inner core as indicated by FTIR-ATR method was richer in carbonate and salts of the fatty acid contents than the outer surface of the stone. But, the cholesterol contents of the outer surface and the entire stone were equal as indicated by the characteristic cholesterol bands in the region between $2800-3000 \mathrm{~cm}^{-1}$ by FTIR and FTIR-ATR respectively. Bilirubin content of the surface and the entire stone were similar as showed by both the FTIR-ATR and regular FTIR methods. It is important to note that the two different aforementioned measurement methods did not demonstrate any significant changes in the cholesterol contents.

\section{Comparison of FTIR spectra of black stones from adults and children}

Comparison of average FTIR spectra of black stones (12 stones) from children and adults (black Type I) is shown in Figures $5 \mathrm{a} \& 5 \mathrm{~b}$ and $6 \mathrm{a} \& 6 \mathrm{~b}$. Our results showed that the spectra of black stones from children (Figure $5 \mathrm{a}: \mathrm{i}$ ) matched with type I obtained from adults (Figure 5a : ii). Type II black stones from adults were rich in cholesterol and less in bilirubin content. The main difference between the children and adults (type II) was the variation in the absorbance in the region between $1000-1100 \mathrm{~cm}^{-1}$. Apart from this variation, the chemical composition of the black stones from children was similar to the adults. The cholesterol content in type I black stones from adults was similar to that of black stones from children (Figure 6a). But, type II stones from adults showed higher cholesterol content compared to the children as indicated in Figure 6b.

\section{FTIR spectra of black and mixed stones from children}

FTIR spectra of a mixed stone and the average of 12 black stones from children are shown in Figure $7 \mathrm{a} \& 7 \mathrm{~b}$. The spectrum of black stone showed characteristic IR bands for bilirubin in the region between $1500-1700 \mathrm{~cm}^{-1}$ as reported in the earlier results. The higher wavenumber region presented in Figure $7 \mathrm{~b}$ indicated that it had reduced cholesterol content. In contrast, the spectra of the mixed stone showed the presence of a large cholesterol content evident by the drastic reduction in the absorbance of bilirubin IR bands (1500-1700 $\left.\mathrm{cm}^{-1}\right)$ and a higher absorbance of the IR bands pertaining to cholesterol in the region between $2800-3000 \mathrm{~cm}^{-1}$. 


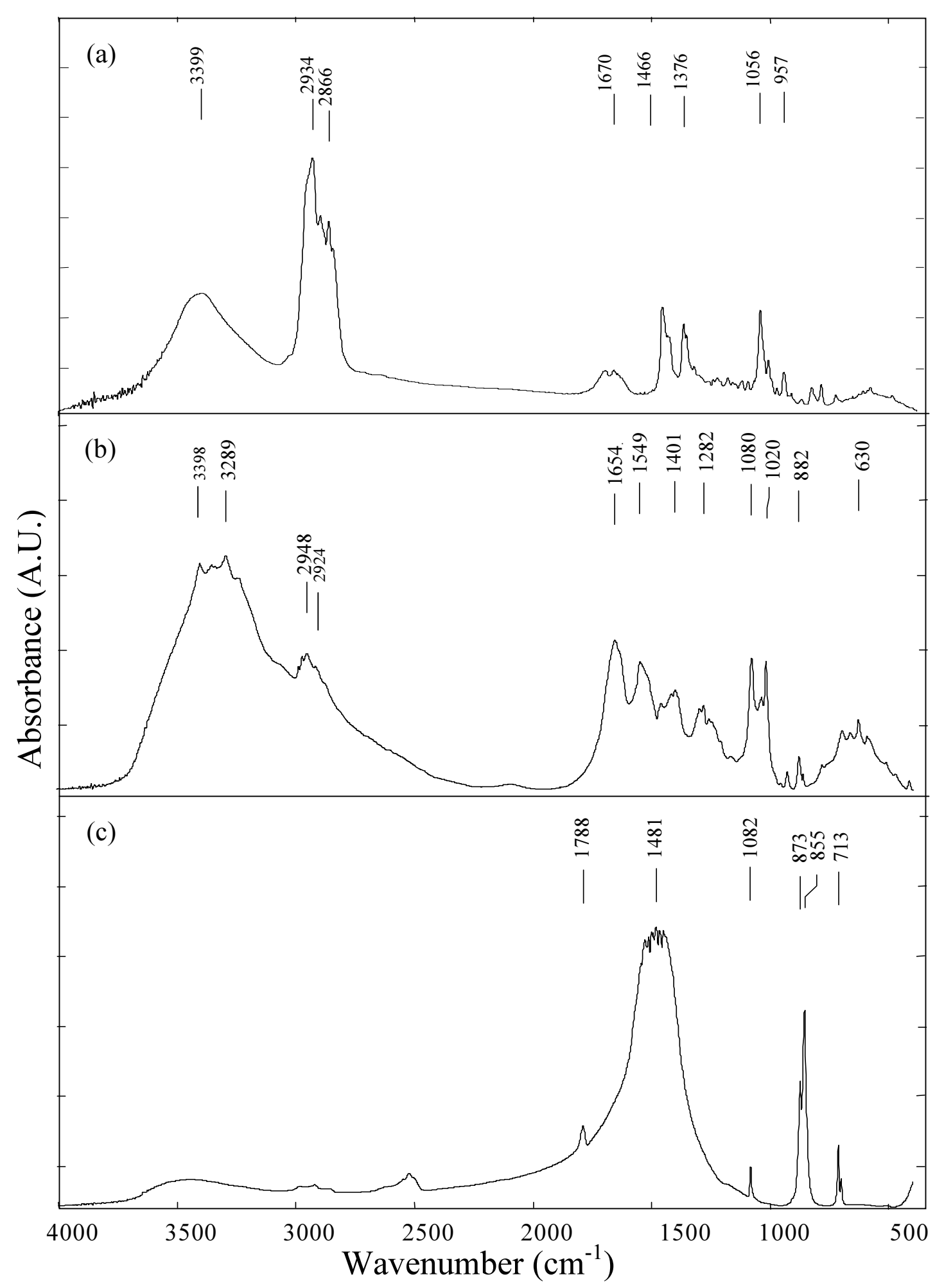

Figure 2

Reference FTIR spectra of pure a) Cholesterol b)Bilirubin c) Calcium carbonate. 
Table I: Type, occurrence and IR bands of principal component observed in gallstones

\begin{tabular}{|c|c|c|c|c|}
\hline Type of Stone & $\begin{array}{l}\text { Occurrence of stones }{ }^{a} \\
\text { (percents) }\end{array}$ & Principal component & $\begin{array}{l}\text { Principal IR bands } \\
\text { observed }\end{array}$ & Literature values (Reference 16). \\
\hline Black I (adult) & 18 & Bilirubin & $\begin{array}{l}1661,1626 \\
1570\end{array}$ & $\begin{array}{l}\text { 1670,1640 (OC=O stretching) } \\
1575(\mathrm{C}=\mathrm{C} \text { stretching) }\end{array}$ \\
\hline Black II (adult) & & Cholesterol & $\begin{array}{l}3398,2933, \\
2866, \\
1463,1376, \\
1053\end{array}$ & $\begin{array}{l}3410,2925\left(\mathrm{CH}_{2} \text { and } \mathrm{CH}_{3} \text { asym- }\right. \\
\text { metric stretching }) \\
2860\left(\mathrm{CH}_{2} \text { and } \mathrm{CH}_{3} \text { symmetric }\right. \\
\text { stretching }) \\
1460, \mathrm{I} 380\left(\mathrm{CH}_{2} \text { and } \mathrm{CH}_{3} \text { bend- }\right. \\
\text { ing) } \\
1050 \text { (C-C stretching) }\end{array}$ \\
\hline Black (child) & 63 & Bilirubin & $\begin{array}{l}1661,1626 \\
157 \mid\end{array}$ & Same as above \\
\hline Brown (adult) & 16 & Cholesterol & $\begin{array}{l}3395,2936 \\
2899,2866 \\
1464,1372 \\
1052\end{array}$ & Same as above \\
\hline $\begin{array}{l}\text { Green inner } \\
\text { core (adult) }\end{array}$ & ND & Cholesterol & $\begin{array}{l}2933,2899 \\
2866, \mid 464 \\
|38|, 1052\end{array}$ & Same as above \\
\hline Mixed (adult) & ND & Cholesterol & $\begin{array}{l}3395,2933 \\
2866,1465 \\
1376,1056\end{array}$ & Same as above \\
\hline
\end{tabular}

ND represents Not Determined. $\mathrm{CaCo}_{3}$ present in green stone gives rise to two characteristic IR bands at I445 and $875 \mathrm{~cm}^{-1}$ due to $\mathrm{C}-\mathrm{O}$ stretching and bending vibrations respectively, ${ }^{\mathrm{T}}$ The listed numbers refer to adults or children.

\section{Fluorescence microscopy of gallstones}

Fluorescence microscopy (FM) has made essential contributions in modern cell biology and medicine [20,21]. In this article, we present the use of this technique in the analysis of gallstones to measure its intrinsic fluorescence. The stones were cut under sterile environment into equal halves to investigate the inner core using fluorescence microscopy. Figure $8 \mathrm{a}, 8 \mathrm{~b}, 8 \mathrm{c}, 8 \mathrm{~d}, 8 \mathrm{e}$ shows the fluorescent micrographs of white and green stones using blue and green filters. The green and blue filters have the excitation range between $480-560$ and $480-490 \mathrm{~nm}$ respectively. Figures $8 \mathrm{a} \& 8 \mathrm{~b}$ show the FM picture of a white stone using green and blue filters. The white stone emitted red and green fluorescence using green and blue filters. Figure $8 \mathrm{c}$ shows a light micrograph of a green stone.

The inner core of the green stone was dark and the outer surface was relatively brighter. This indicated that the inner core may contain a pigment like bilirubin and the outer surface could be made up of cholesterol. The green stone emitted red fluorescence using both filters. But, the intensity of red fluorescence was higher using a green filter than with a blue filter. Interestingly, ring patterns were clearly observed in the green stone using both filters (Figure $8 \mathrm{~d} \& 8 \mathrm{e})$.

\section{Discussion}

Gallstone disease is still one of the most common digestive diseases with an overall prevalence of $10 \%$ in the United States [22,23]. Since the pathogenesis of gallstones is not clearly understood, its analysis-using chemical and spectroscopic techniques have provided some clues $[24,25]$. Our studies reported herein on children are of special significance as there are no such earlier reports on children in the literature.

The results on black stones suggest that the composition of bilirubin and cholesterol varies considerably. This is clear from Figure 1a \& 1b where Type I black stone had a higher bilirubin and a lower cholesterol content in contrast to type II black stone. This was observed consistently in other black stones obtained from adult patients. From the absorbance of black and brown stones in the region between $1500-1800 \mathrm{~cm}^{-1}$, it can be deduced that the bilirubin content of black stones was much higher than that of brown stones in adults. In addition, brown stones had a higher cholesterol / bilirubin ratio compared to the black stones.

None of the black stones from children contain as much cholesterol as type II black stones from adults. Therefore, we hypothesize that children do not have as many stones 


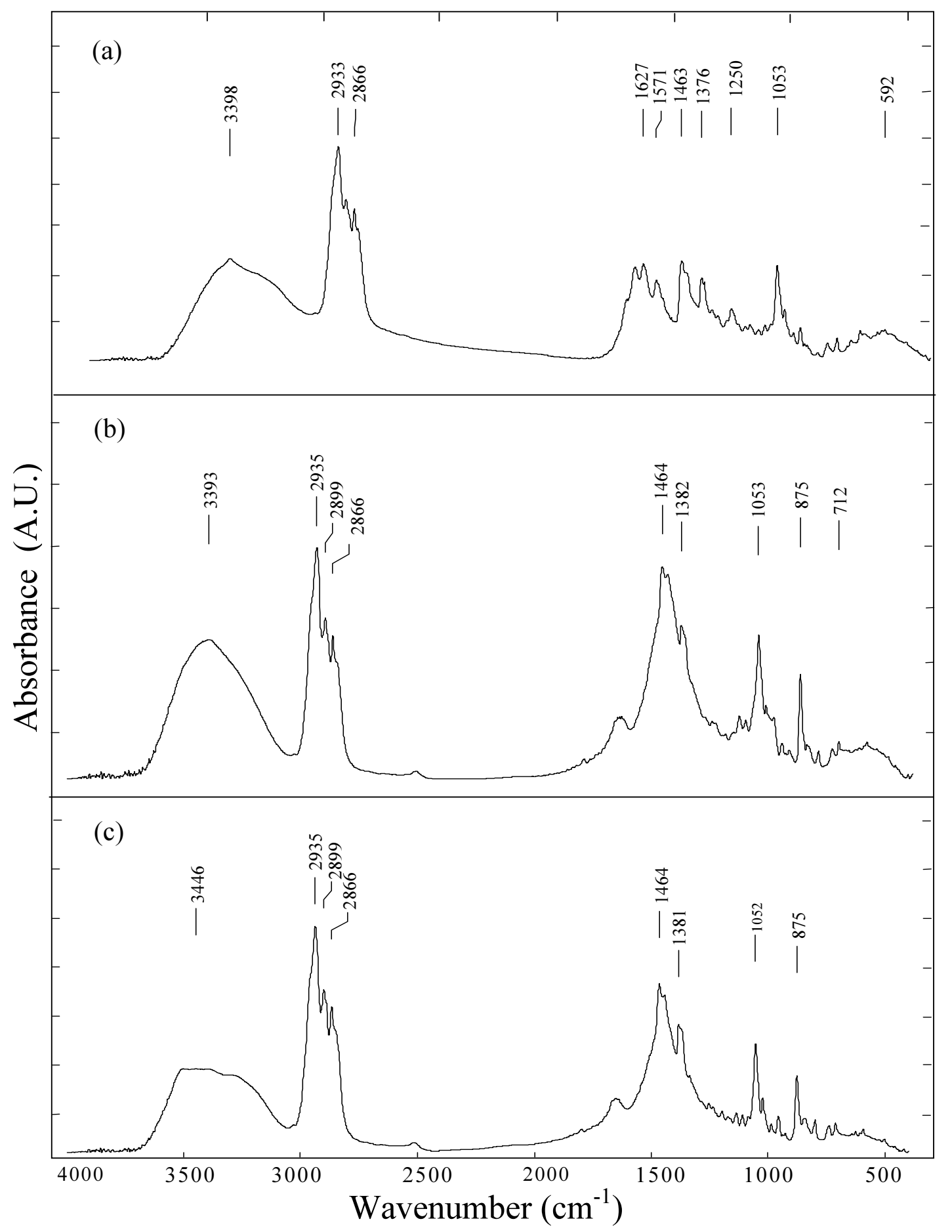

Figure 3

FTIR spectra of a) Average of many type II black stones from adult patients b) Outside surface of green stone c) Inner core of green stone from an adult patient. 

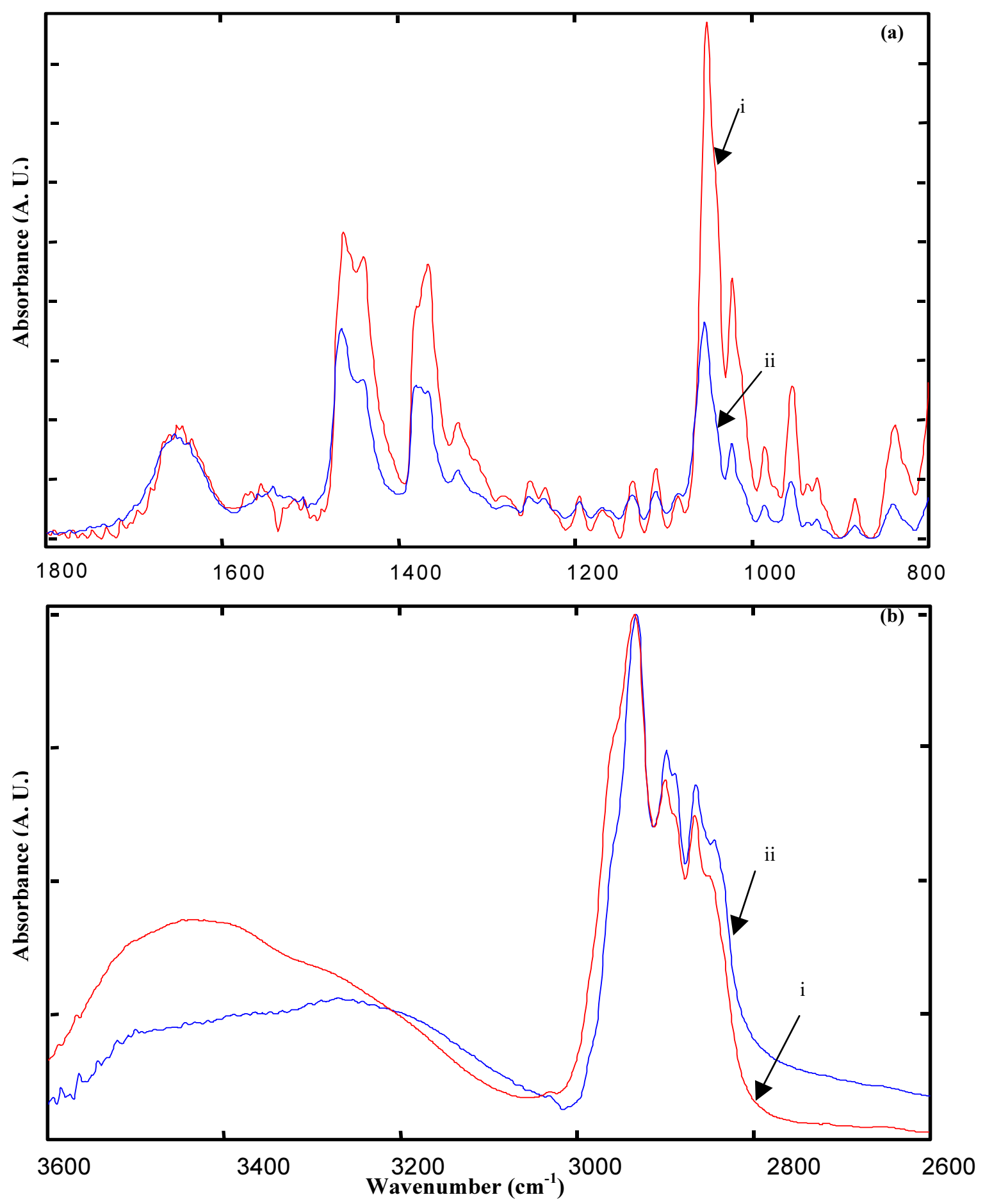

Figure 4

a \& b i) FTIR-ATR spectrum of entire brown stone ii) Regular FTIR spectrum of outside surface of a brown stone. Both measurements were made from a single stone from a patient. 

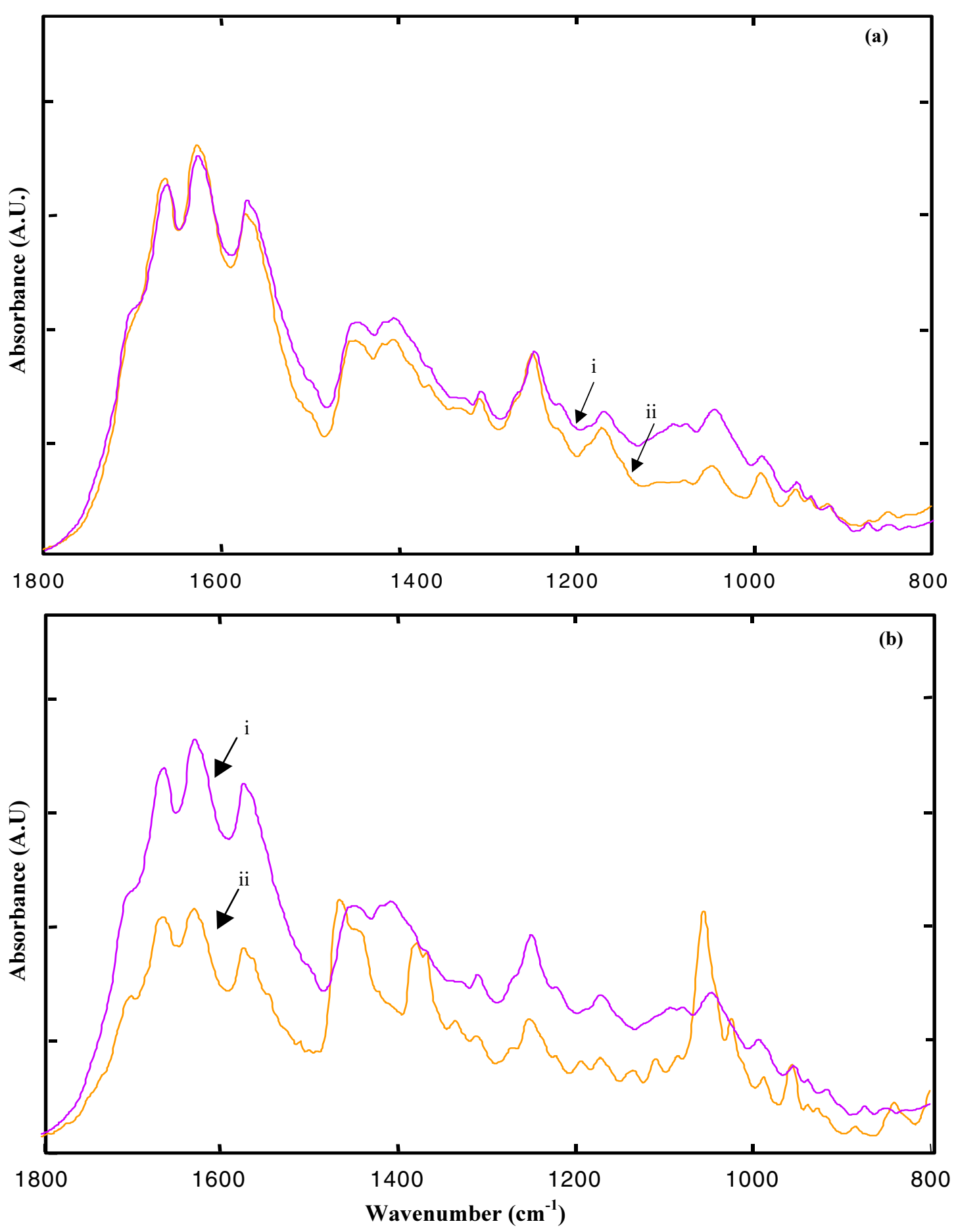

Figure 5

a \& b FTIR spectra of i) black stone from children ii) black stone from adult patients in the region between $800-1800 \mathrm{~cm}^{-1}$. Black stones from adults type I and II are shown in Figures 5a, 6a and 5b, 6b respectively. In the case of adults and children, average spectra of 12 stones are presented. 

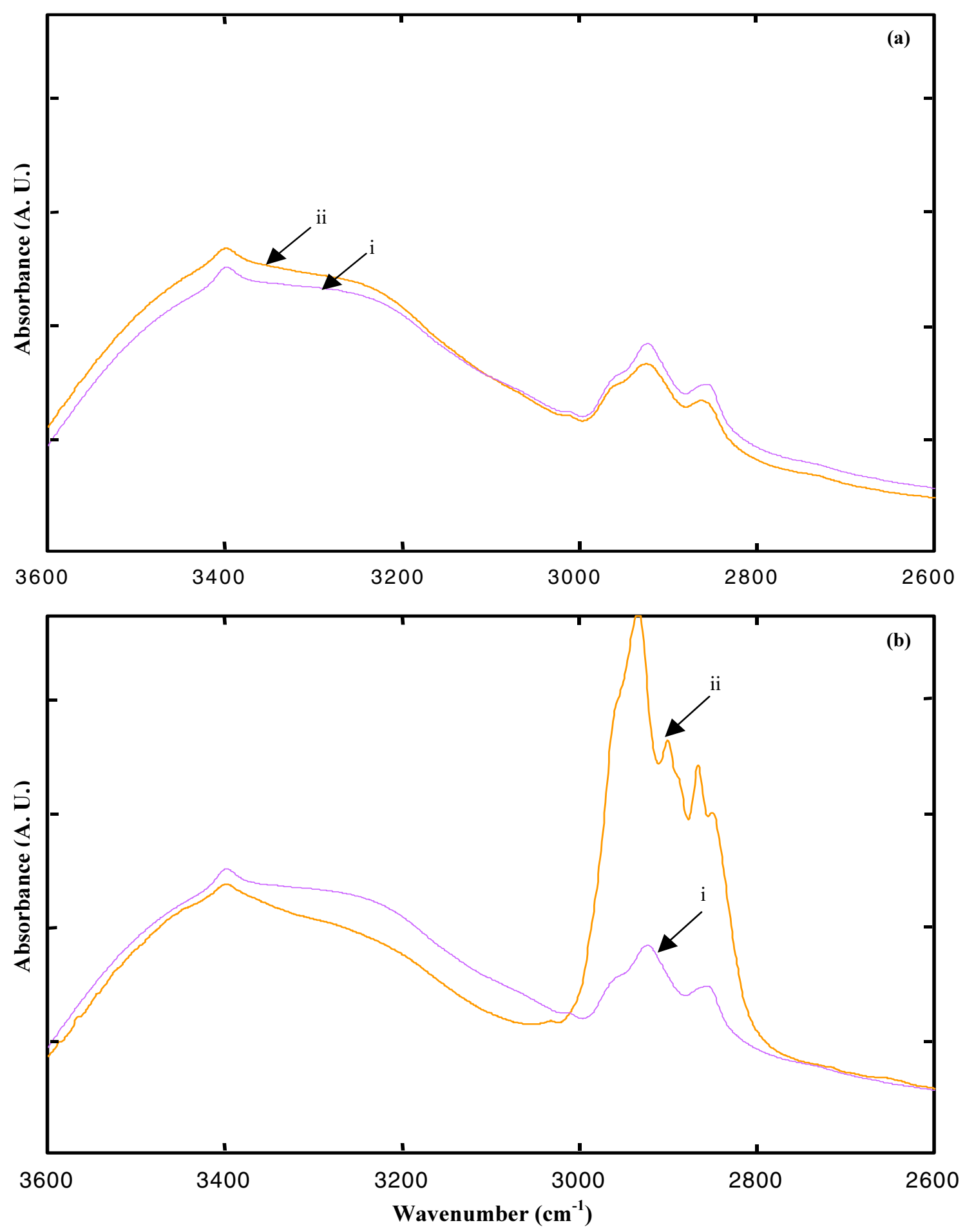

Figure 6

a \& b FTIR spectra of i) Average of 12 black stones from children ii) Type II black stone from 12 adult patients in the region between $2600-3600 \mathrm{~cm}^{-1}$. Black stones type I and II from adults are shown in the Figures $6 \mathrm{a}$ and $6 \mathrm{~b}$ respectively. 

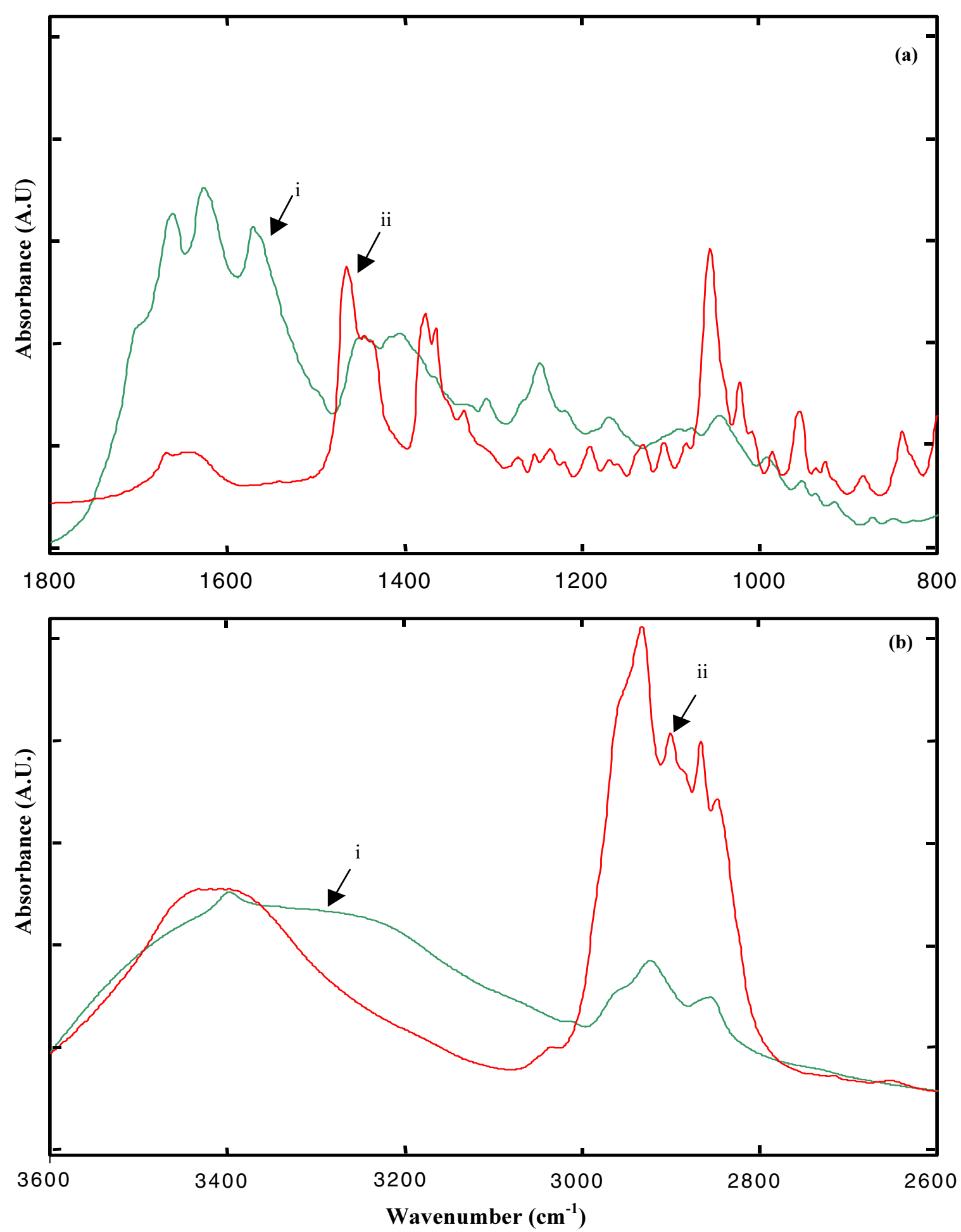

Figure 7

a \& b FTIR spectra of i) Average of 12 black stones from children ii) mixed stone from a child. 

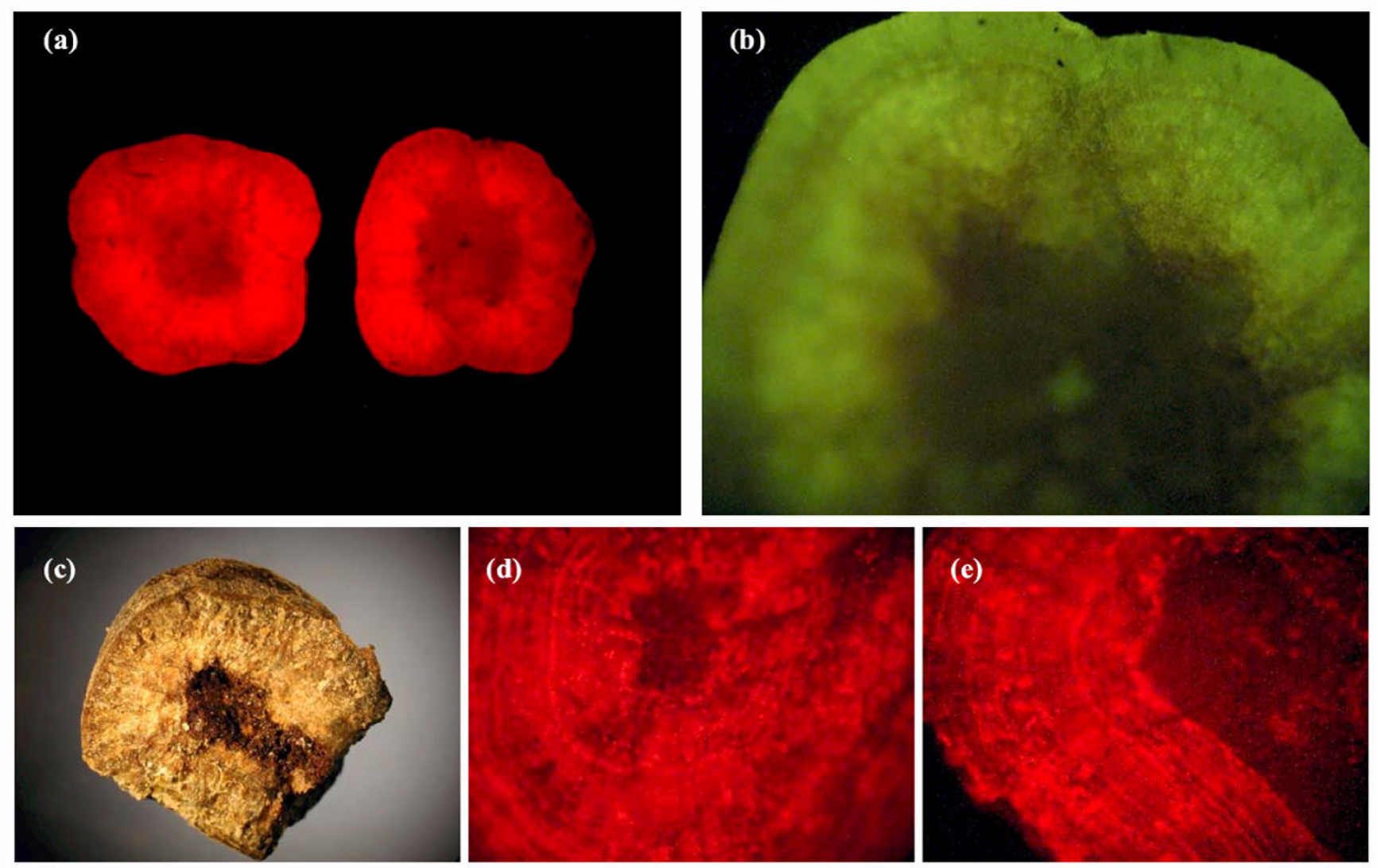

\section{Figure 8}

Fluorescent microscopic pictures of a) Inner core of mixed stone using green filter b) Inner core of one part of white stone using blue filter d) Inner core of green stone using green filter e) Inner core of green stone using blue filter. Green and blue filter excitation ranges are $480-560$ and $480-490 \mathrm{~nm}$ respectively. Figure $8 \mathrm{c}$ is the light microscopic picture of the green stone. Both stones were obtained from adults.

with a high percentage of cholesterol. Accordingly, the percentage of brown stones in children is expected to be dramatically less. Our data based on children revealed that the percentage of brown stones in children was only $5 \%$ whereas the percentage increased to $16 \%$ in adults. However, the percentage of black stones in children was $63 \%$. It is interesting to note that our FTIR results are in good agreement with these facts and the figures available in the clinical database. Our study on children was limited, however, it clearly indicates that bilirubin is a major risk factor for the GSD in children whereas cholesterol would be in adults. More extensive studies are required to confirm these findings.

The FTIR spectral analysis of black stones from adults and mixed stones from children showed that bilirubin was dominant in black stones and cholesterol in mixed stone. Since cholesterol may not be a risk factor in children, the number of white stones among them is rare and our database also supports this observation. The composition of a given type of gallstones in children is similar to the adults and therefore, the mechanism or factors responsible for stone formation might be also the same in both children and adults. Detailed investigation on the pathogenesis of gallstone formation in children may provide additional necessary understanding in the future.

Green stones are rare among all the known pigmented stones. Surprisingly, the composition of the green stone is similar to that of white stones having a very high content of cholesterol. In addition, dominant bands at 1052 and $875 \mathrm{~cm}^{-1}$ indicated that the green stone had a high content of cholesterol and calcium carbonate.

The band at $875 \mathrm{~cm}^{-1}$ is due to the bending vibration of $\mathrm{CO}_{3}{ }^{2-}$ in calcium carbonate. FTIR was unable to provide information about the green color pigment present in the green stone. FTIR-ATR of the whole stone and regular FTIR of the surface of brown stone from adults showed that the cholesterol content was similar in both methods. Howev- 
er, FTIR-ATR showed increased content of fatty acids and carbonate. Hence, it can be concluded that the inner core of the stone had more of fatty acids and calcium carbonate, which could have initiated the nucleation events for the stone formation.

Fluorescence microscopy on the inner core of gallstones revealed the differences in their chemical composition, which correlated well with FTIR spectroscopy. All the stones (including brown and black stones for which the data are not shown) emitted red fluorescence using a green filter. This red fluorescence emission may be due to Ca-bilirubinate complex present in the stones. The mixed stone emitted green fluorescence using a blue filter was observed due to Cu-bilirubinate, which is present only in mixed and black stones. In black stones, occurrence of polymerized Cu-bilirubinate complex was already reported in the literature $[7,26,27]$. Even though copper is reported to be present in the brown stone [7], we rule out the possibility of the presence of Cu-bilirubinate complex in the brown stones. In brown and green stones, red fluorescence was observed using both filters. The difference in the chemical composition can be attributed to the various mechanisms responsible for the pathogenesis of gallstones. Certain types of bacteria are detected only in the brown stones $[28,29]$. Black stones are associated with hemolysis and liver cirrhosis.

The cross-section of the brown gallstones are seen to have concentric ring patterns [30]. Our FM micrograph of a green stone showed regular ring patterns, which are seen clearly using the blue filter. The explanation for this observation is the periodic precipitation of various bile acids along with proper combination of metal ions. Periodic patterns in biological systems can offer clues to their origin and further analysis may brighten the understanding of the mechanism of the formation of gallstones. Pathogenesis of gallstones is as yet poorly understood. Detailed studies using a battery of spectroscopic and microbiological methods will probably lead to a better understanding of gallstone formation leading to better prevention in the first place.

\section{Conclusions}

FTIR and fluorescence microscopic studies on different types of gallstones from adults and children have shed light on their chemical composition. Black stones from adults had varying amounts of bilirubin, and brown stones were rich in cholesterol. Comparison of black stones from adults and children suggested that bilirubin and cholesterol might be the risk factors in children and adults respectively. The main composition of black stones from adults and children were found to be similar using FTIR spectroscopy. A new green color stone from an adult, which is rare, has also been reported in our study. The analysis showed that the principal components of the green stone were cholesterol and calcium carbonate. It is interesting to note that the contents of cholesterol and calcium carbonate were higher in the inner core of the brown stones compared to that of outer surface. Fluorescence microscopic analysis indicated that the mixed and black stones had both Ca-bilirubinate and Cu-bilirubinate. The brown and green stones contained only Ca-bilirubinate. The specific ring patterns found in the green stone are interesting and needs further investigation.

\section{List of abbreviations}

FTIR : Fourier Transform InfraRed;

FM : Fluorescence Microscopy;

HATR : Horizontal Attenuated Total Reflection;

GFP : Green Fluorescent Protein;

YFP : Yellow Fluorescent Protein;

GSD : GallStone Disease;

SUMC : Soroka University Medical Center.

\section{Competing Interests}

None declared

\section{Acknowledgements}

We gratefully acknowledge the research grant from the Faculty of Health at Ben Gurion University of the Negev received by Dr. Jacov Mordehai during the course of this work. We also acknowledge the Harry-Stern Applied Research Grant Program for partial support.

\section{References}

I. Harding AJ: Gallstones: Causes and Treatments. William Heinemann Medical Books, London, 1964

2. Kern F, Jr : Epidemiology and natural history of gallstones. Semin. Liver. Dis 1983, 3:87-96

3. Swidsinski A, Khilkin M, Pahlig H, Swidsinski S, Priem F: Time dependent changes in the concentration and type of bacterial sequences found in cholesterol gallstones. Hepatology 1998, 27:662-665

4. Kumar R, Nguyen K, Shun A: Gallstones and common bile duct calculi in infancy and childhood Aust. N. Z. J. Surg 2000, 70:188|9|

5. Lobe TE: Cholelithiasis and Cholecystitis in children Semn. Ped. Surg 2000, 9:170-176

6. Waldhausen $\mathrm{JH}$, Benjamin DR: Cholecystectomy is becoming an increasingly common operation in children. Am. J. Surg 1999, 177:364-367

7. Paluszkiewicz C, Kwiatek WM, Galka M, Sobieraj D, Wentrup-Byrne D: FT-Raman, FT-IR spectroscopy and PIXE analysis applied to gallstones specimens Cell. Mol. Biol 1998, 44:65-73

8. Trotman BW, Soloway RD: Pigment gallstone disease: summary of the National Institutes of Health-International Workshop. Hepatology 1982, 2:879

9. Roslyn J, Zinner MJ: Principles of Surgery 1994 I376-1399

I0. Mantsch HH, Chapman D: Infrared Spectroscopy of Biomolecules John Wiley, N.Y, 1996

II. Gao T, Feng J, Ci Y: Human breast carcinomal tissues display distinctive FTIR spectra: implication for the histological characterization of carcinomas Anal. Cell. Pathol. I 999, 1 8:87-93 
12. Wang $\mathrm{H}$, Wang HC, Huang Y]: Microscopic FTIR studies of lung cancer cells in pleural fluid Sci. Total. Environ. 1997, 204:283-287

13. Salman A, Argov S, Jagannathan Ramesh., Goldstein J, Sinelnikov I, Guterman $\mathrm{H}$, Mordechai S: FTIR microscopic characterization of normal and malignant human colonic tissues. Cell. Mol. Biol (Nosiy-le-grand) 200I, 47:OLI59-OLI66

14. Zhou X, Wu J, Soloway RD: Application of Spectroscopy in the study of pigment gallstone in China. Biospectroscopy 1997, 3:195205

15. Estepa L, Daudon M: Contribution of Fourier transform infrared Spectroscopy to the identification of urinary stones and kidney crystal deposits. Biospectroscopy 1997, 3:347-369

16. Zhou X-S, Shen G-R, Wu J-G, Li W-H, Xu Y-Z, Weng S-F, Soloway RD, Fu X-B, Tian W, Xu Z, Shen T, Xu G-X, Wentrup-Byrne E: A Spectroscopic study of pigment gallstones in China. Biospectroscopy 1997, 3:37I-380

17. Wentrup-Byrne E, Chua-Anusorn W, St Pierre TG, Webb J, Ramsay A, Rintoul L: A Spectroscopic study of thalassemic gallstones, Biospectroscopy 1997, 3:409-416

18. Vigano C, Manciu L, Buyse F, Goormaghtigh E, Ruysschaert JM: Attenuated total reflection IR spectroscopy as a tool to investigate the structure orientation and tertiary structure changes in peptides and membrane proteins. Biopolymers 2000 , 55:373-380

19. Chittur KK: FTIR/ATR for protein adsorption to biomaterial surfaces. Biomaterials 1998, 19:357-369

20. Gustafsson MG: Extended resolution fluorescence microscopy. Curr. Opin. Struct. Biol. 1999, 9:627-634

21. Robinson JM, Takizawa T, Pombo A, Cook PR: Correlative fluorescence and electron microscopy on ultrathin cryosections bridging the resolution gap J. Histochem. Cytochem 200I, 49:803808

22. Afdhal NH: Crohn's and Stones. The Am. J. Gastroent, 1999, 94:1130-1132

23. Kratzer W, Mason RA, Kächele V: Prevalence of gallstones in sonographic surveys worldwide $J$. Clin. Ultrasound 1999, 27: I-7

24. Wentrup-Byrne E, Rintoul L, Smith JL, Fredericks PM: Comparison of vibrational Spectroscopic techniques for the characterization of human gallstones. Appl. Spectrosc. 1995, 49: I028-1036

25. Wu J-G, Zhou X-S, Xu Z, Shen T, Xu Y-Z, Li W-H, Xu D-F, Soloway RD, Wentrup-Byrne E, Xu Z-H, Shi G-R, Deng S-Q, Li X-F, Shi N: A spectroscopic investigation of the formation mechanism of pigment gallstones. Biopsetroscopy 1997, 3:38I-39I

26. Shizsuma K, Iwatani K, Hasai H, Wen XQ, Horiuchi I, Kajiyama G: PIXE analysis of gallstones: trace element analysis and millibeam scanning of stone sections. Nucl. Instr. Meth. Phys. Res. | 997, B | 29:40|-409

27. Li W-H, Shen G-R, Soloway RD, Yang Z-L, Tong X-B, Wu E, Xu D-F, Wu J-G, Xu G-X: Copper bilirubinate and black pigment gallstone Biospectroscopy, 1995, I: I 49-156

28. Wetter LA, Hamadeh RM, Griffiss JM, Oesterle A, Aagaard B, Way LW: Differences in outer membrane characteristics between gallstone-associated bacteria and normal bacterial flora. Lancet 1994, 343:444-448

29. Swidsinski A, Ludwig W, Pahlig H, Priem F: Molecular genetic evidence of bacterial colonization of cholesterol gallstones. Gastroenterology 1995, 108:860-864

30. Wu J-G, Xu D-F, Liu F, Zhou X-S, Zhang Y-F, Zhou N-F, Hong N-K, Soloway RD: Do ring form in gallstone during growth due to the Liesegang phenomenon or periodic deposition? Gastroenterology 1990, 98:A256
Publish with BioMed Central and every scientist can read your work free of charge

"BioMedcentral will be the most significant development for disseminating the results of biomedical research in our lifetime." Paul Nurse, Director-General, Imperial Cancer Research Fund

Publish with BMC and your research papers will be:

- available free of charge to the entire biomedical community

- peer reviewed and published immediately upon acceptance

- cited in PubMed and archived on PubMed Central

- yours - you keep the copyright

Submit your manuscript here:

http://www.biomedcentral.com/manuscript/

BioMedcentral.com ditorial@biomedcentral.com 